29_ Allergische Rhinitis

34_ CME-Fragen

35- ASS-Intoleranz-Syndrom

Eine Patienteninformation zum

Thema „Heuschnupfen “ finden Sie im Internet unter www.mmw.de.

\title{
事
}

Steigende Prävalenz, hohe Kosten

\section{Wir haben den Heuschnupfen noch immer nicht im Griff}

- Allergische Erkrankungen sind in den Industrienationen seit geraumer Zeit auf dem Vormarsch - und dies mit weiter steigender Tendenz. Dabei repräsentiert die allergische Rhinitis (AR) mit einer Lebenszeitprävalenz von $24 \%$ die häufigste Immunkrankheit. Auch unter den chronischen Erkrankungen spielt sie eine führende Rolle.

Doch nur jeder dritte Patient mit AR wird nach Einschätzung der Deutschen Gesellschaft für Allergologie und Immunologie (DGAI) überhaupt und nur jeder zehnte leitlinienkonform behandelt. Betrachtet man andererseits die Kosten für allergische Atemwegserkrankungen insgesamt, die direkt oder indirekt durch die AR und deren Folgeerkrankungen entstehen können (jährlich ca. fünf Milliarden $€$ ), werden exemplarisch die Defizite des deutschen Gesundheitssystems sowie die Auswirkungen einer seit Jahren völlig fehlgesteuerten Gesundheitspolitik deutlich.

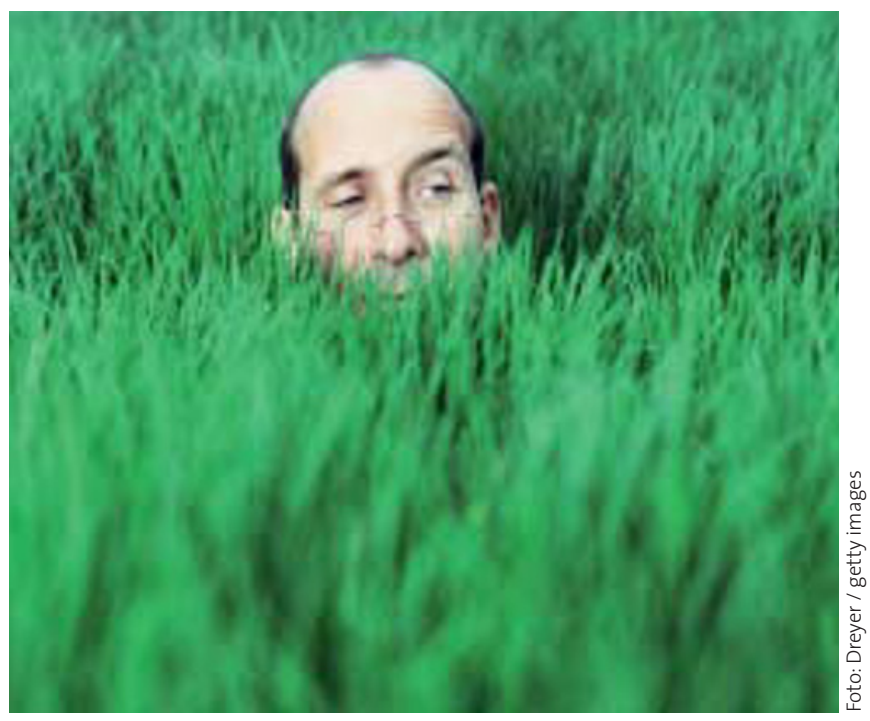

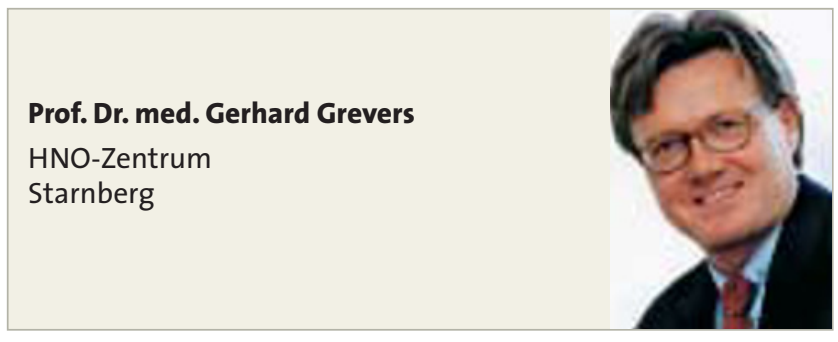

Die symptombezogene medikamentöse Therapie der AR erfolgt heute im Wesentlichen über topische Steroide und orale Antihistaminika. Darüber hinaus bildet die Immuntherapie einen wichtigen Pfeiler der Behandlung. Obwohl das Prinzip dieses einzigen kausalen Therapieansatzes bei der AR seit fast 100 Jahren bekannt ist, hat dieser erst in den vergangenen Jahrzehnten zunehmend an Bedeutung gewonnen.

Mit der Zunahme allergischer Erkrankungen erhöhte sich der Stellenwert der Immuntherapie auch unter wirtschaftlichen Gesichtspunkten. Denn sie trägt dazu bei, den Verbrauch symptombezogener Medikamente zu senken und Folgeerkrankungen zu verhindern. Ein Problem war für viele Patienten bislang oft der mit der Behandlung verbundene Zeitaufwand. Neue Ansätze, die Dosierungssteigerungsphase abzukürzen, haben, wie der folgende Beitrag darstellt, wesentliche Fortschritte gebracht und dürften die Akzeptanz der Immuntherapie weiter verbessern.

Eine wichtige Differenzialdiagnose bei chronisch entzündlichen Erkrankungen der oberen und unteren Atemwege ist das ASS-Intoleranzsyndrom. Die Prävalenz der Erkrankung ist zwar in der Normalbevölkerung mit 0,5-5,7\% vergleichsweise niedrig, steigt aber bei Asthmatikern und Patienten mit Polyposis nasi auf bis zu 15\% an. Deshalb erläutert der zweite Beitrag dieses Schwerpunkts die klassischen Symptome, das diagnostische Vorgehen sowie die Therapieoptionen bei diesem Krankheitsbild. 